\title{
Assessing of channel structure and magnetic properties on heavy metal ions removal from water
}

Ebtesam Ateia ( $\nabla$ drebtesam2000@yahoo.com )

Cairo University https://orcid.org/0000-0002-6100-8220

Mahmoud A. Ateia

Cairo University

Mohamed Arman

Cairo University

\section{Research Article}

Keywords: isothermal models, adsorption process, lead removal, Li nano ferrite, spacing parameters

Posted Date: March 22nd, 2021

DOI: https://doi.org/10.21203/rs.3.rs-312141/v1

License: (1) This work is licensed under a Creative Commons Attribution 4.0 International License.

Read Full License

Version of Record: A version of this preprint was published at Journal of Materials Science: Materials in Electronics on October 9th, 2021. See the published version at https://doi.org/10.1007/s10854-02107008-9. 


\title{
Assessing of channel structure and magnetic properties on heavy metal ions removal from water
}

\author{
Ebtesam E. Ateia ${ }^{1,2 *}$, Mahmoud A. Ateia ${ }^{1}$, M.M. Arman ${ }^{1}$ \\ 1Physics Department, Faculty of Science, Cairo University, Giza, Egypt \\ 2 Academy of Scientific Research and Technology (ASRT), Egypt
}

\begin{abstract}
:
The synthesis of $\mathrm{Li}_{1.1} \mathrm{Co}_{0.3} \mathrm{Fe}_{2.1} \mathrm{O}_{4}$ ferrite nanoparticles has been synthesized by the citrate auto combustion method. The distribution of cations on A-site and B-site was studied by X-ray Diffraction (XRD), High- Resolution Transmission Electron Microscopy (HRTEM). The crystallite size and strain were calculated by using the $\mathrm{W}-\mathrm{H}$ (Williamson-Hall) plot. The crystallite of $\mathrm{Li}_{1.1} \mathrm{Co}_{0.3} \mathrm{Fe}_{2.1} \mathrm{O}_{4}$ ferrite nanoparticle is $\sim 30 \mathrm{~nm}$. HRTEM confirmed the homogeneous formation of the cubic phase. The calculated height and spacing parameters related to roughness are essential to achieve the efficiency of $\mathrm{Li}_{1.1} \mathrm{Co}_{0.3} \mathrm{Fe}_{2.1} \mathrm{O}_{4}$ to be used in microbatteries, smart windows, smart mirrors, displays, gas sensors, and other applications. According to the obtained data, the $\mathrm{Li}_{1.1} \mathrm{Co}_{0.3} \mathrm{Fe}_{2.1} \mathrm{O}_{4}$ has a spiky surface with $\mathrm{R}_{\mathrm{ku}}=5.50$. Additionally, the magnetic hysteresis loop has been clarified using the Vibrating Sample Magnetometer (VSM). The double peak characteristic in the Switching field distribution (SFD) reveals the competition between exchange coupling and strong dipolar interactions. $\mathrm{Li}_{1.1} \mathrm{Co}_{0.3} \mathrm{Fe}_{2.1} \mathrm{O}_{4}$ has employed as a sorbent material for the removal of lead (II) ions from wastewater. The main advantages of the synthesized sample are ease of separation, high adsorption, low cost as well as recycled with notable efficiency. Two models of adsorption isotherms (Freundlich and Langmuir) are utilized to recognize the adsorption mechanism.
\end{abstract}

Keywords: isothermal models, adsorption process, lead removal, Li nano ferrite, spacing parameters.

\section{Introduction}

A great properties of spinel ferrites are inexpensive, abundant in nature, environment-friendly and more stable.

Lithium ferrite in the spinel structure is a low-cost material that, is generally valuable for a number of unique electromagnetic properties of that enlarges the scope their application in various devices of modern microwave technology[1-2]. They also can be used as cathode materials in lithium-ion batteries [3]. and as sensing units in gas sensors [4]. It has a highresistivity, low mobility semiconductor, and low eddy current losses. The properties of lithium ferrite can be enhanced by the substitution of divalent (cobalt) ions.

The spinel cobalt ferrite $\left(\mathrm{CoFe}_{2} \mathrm{O}_{4}\right)$ materials have great attention due to their special physical Corresponding author: drebtesam2000@yahoo.com 
and catalytic properties. It was studied in several fields of electrocatalysts [5], chemical sensors[6-7], Li-ion batteries [8-9], and supercapacitors [10-11]. The structure of $\mathrm{CoFe}_{2} \mathrm{O}_{4}$ has an inverse spinel structure, signified as $\left(\mathrm{Fe}^{3+}\right)\left[\mathrm{Co}^{2+} \mathrm{Fe}^{3+}\right] \mathrm{O}_{4}$, where $\mathrm{Fe}^{3+}$ ions occupied one-eighth of the tetrahedral sites (A sites) and $\mathrm{Co}^{2+}$ and $\mathrm{Fe}^{3+}$ ions occupied one-half of the octahedral sites (B sites) ions [12-13]. This structure has revealed good magnetic, optical, and electrical conductivity [14-15].

Removal of Heavy Metals from wastewater is a significant issue because they not only contaminate the water bodies but are also toxic to the ecosystem. As the majority of the heavy metals are non-degradability and highly toxic in nature. Consequently, their concentrations have to be decreased to appropriate levels before discharging into the environment, or else these can cause a threat to human as well as animal health.

In the present study, $\mathrm{Li}_{1.1} \mathrm{Co}_{0.3} \mathrm{Fe}_{2.1} \mathrm{O}_{4}$ is synthesized using the citrate precursor method because of its cost - effectiveness, homogeneous formation of cubic ferrites, less time-consuming technique, and uniform particle size. Structural, thermal analysis morphological, and magnetic investigations were performed on the investigated sample. Further, the sample was employed as a sorbent for the removal of heavy metal (lead II) from water. The effect of $\mathrm{pH}$ on the adsorption process has been studied.

\section{Experimental Work}

\subsection{Preparation technique}

All chemicals were purchased from Sigma-Aldrich. $\mathrm{LiCoFeO}$ was prepared by mixing nonstoichiometric proportions of iron, cobalt, lithium nitrates with a calculated amount of citric acid by citrate auto combustion technique as reported previously [16] with some adjustments as shown in Fig. 1a

\subsection{Adsorption test}

The batch equilibrium technique was employed as mentioned in the previous work [17]. The $\mathrm{Pb} 2+$ ion concentration was measured by atomic absorption spectrophotometry ICP (spectrometry Prodigy7). 


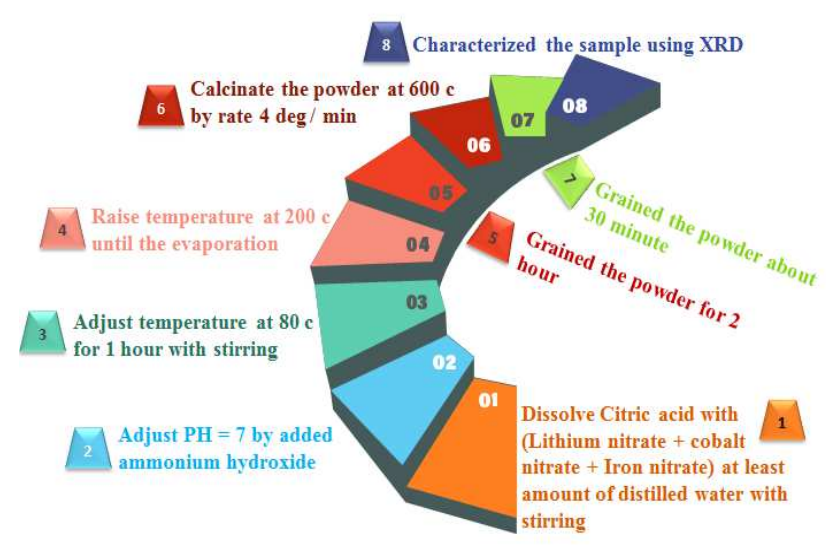

(a)

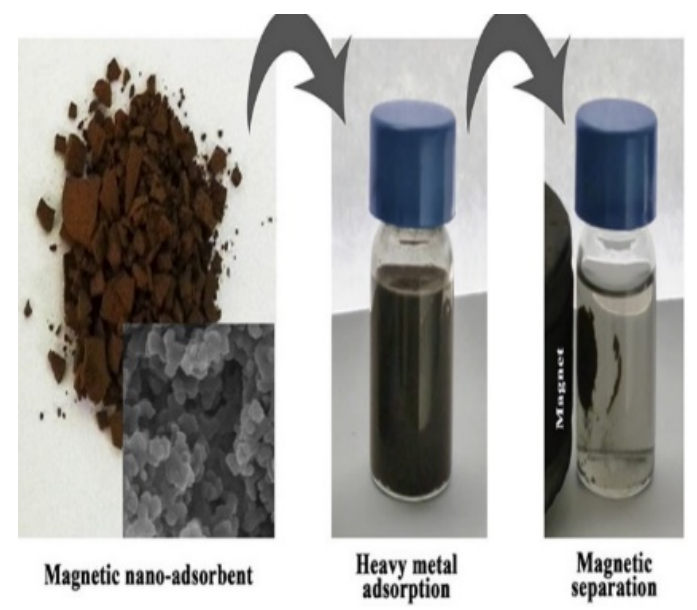

(b)

Fig. 1: a-b Flowchart for the synthetic scheme and the recovery of $\mathrm{Li}_{1.1} \mathrm{Co}_{0.3} \mathrm{Fe}_{2.1} \mathrm{O}_{4}$ from water by a small magnet

The adsorption efficiency $(\eta)$ and the equilibrium adsorption capacity (q) of metal ions were calculated according to the following equations [18]

$$
\begin{aligned}
& \eta=\frac{C_{i}-C_{e}}{C_{i}} \times 100 \\
& q=\frac{\left(C_{i}-C_{e}\right) V}{m}
\end{aligned}
$$

Where $C_{i}$ and $C_{e}$ are the initial and equilibrium (final) concentrations (mg/L) of metal ion solution, respectively. While $\mathrm{V}$ and $\mathrm{m}$ are the volume of $\mathrm{Pb}$ (II) solution, and the mass of adsorbent respectively. The nano ferrite sample is attracted to the magnet and accordingly can be easily separated as illustrated in Fig. 1b.

\section{Results and discussion:}

$\mathrm{Li}_{1.1} \mathrm{Co}_{0.3} \mathrm{Fe}_{2.1} \mathrm{O}_{4}$ exhibits a non-stoichiometry. The non-stoichiometry may occur for some ferrite materials in which two valence states exist for one of the ion types. It is due to an excess positive charge which must be offset by some types of defects. This may be accomplished by the oxidation and reduction processes of cations like $\mathrm{Fe}^{3+}$ and $\mathrm{Fe}^{2+}$ during the auto combustion. In fact, the chemical formula is often written as $\mathrm{Me}_{1-x} \mathrm{M}_{x} \mathrm{Fe}_{2} \mathrm{O}_{4}$ to indicate a condition of non-stoichiometry with an excess of cations. 
Figure 2a illustrates the XRD pattern of the $\mathrm{Li}_{1.1} \mathrm{Co}_{0.3} \mathrm{Fe}_{2.1} \mathrm{O}_{4}$ sample revealing the formation of cubic spinel phase with space group (Fd-3m). The XRD data is compared with JCPDS card 04022-8066. There are no appreciable impurity peaks in the spectrum of the sample. The indexed peaks are (220), (311), (222), (400), (422), (511), (440), (620) and (533). The more intense peak is observed at $2 \theta=35.73^{\circ}$ with hkl (311) which agrees well with the reported literature [19].

Certainly, the stoichiometric ratio for the tetra /octa is 0.50 causes a single spinel phase. In the present study, this ratio equals 0.66 yielding an excess amount of metals. In fact, the XRD pattern does not detect any secondary phases. This can be attributed to the large surface-tovolume ratio leading to the flexibility of the structure as well as the flexibility of the composition [20]. Li-ferrite nanoparticles show a partially inverted spinel structure [21]. The incorporation of the two cations at both cationic lattice sites of the spinel structure allows a broad compositional range of stability, even with rich compositions (cations in $\mathrm{A} /$ cations in $\mathrm{B}>0.5$ ). Additionally, this non-stoichiometry can be structurally accommodated by the formation of point defects.

The crystallite size (DXRD) and the average lattice strain $(\varepsilon)$ of $\mathrm{Li}_{1.1} \mathrm{Co}_{0.3} \mathrm{Fe}_{2.1} \mathrm{O}_{4}$ can be detected according to the Williamson-Hall equations [22]:

$$
\beta \cos \theta=4 \epsilon \sin \theta+\frac{K \lambda}{D}
$$
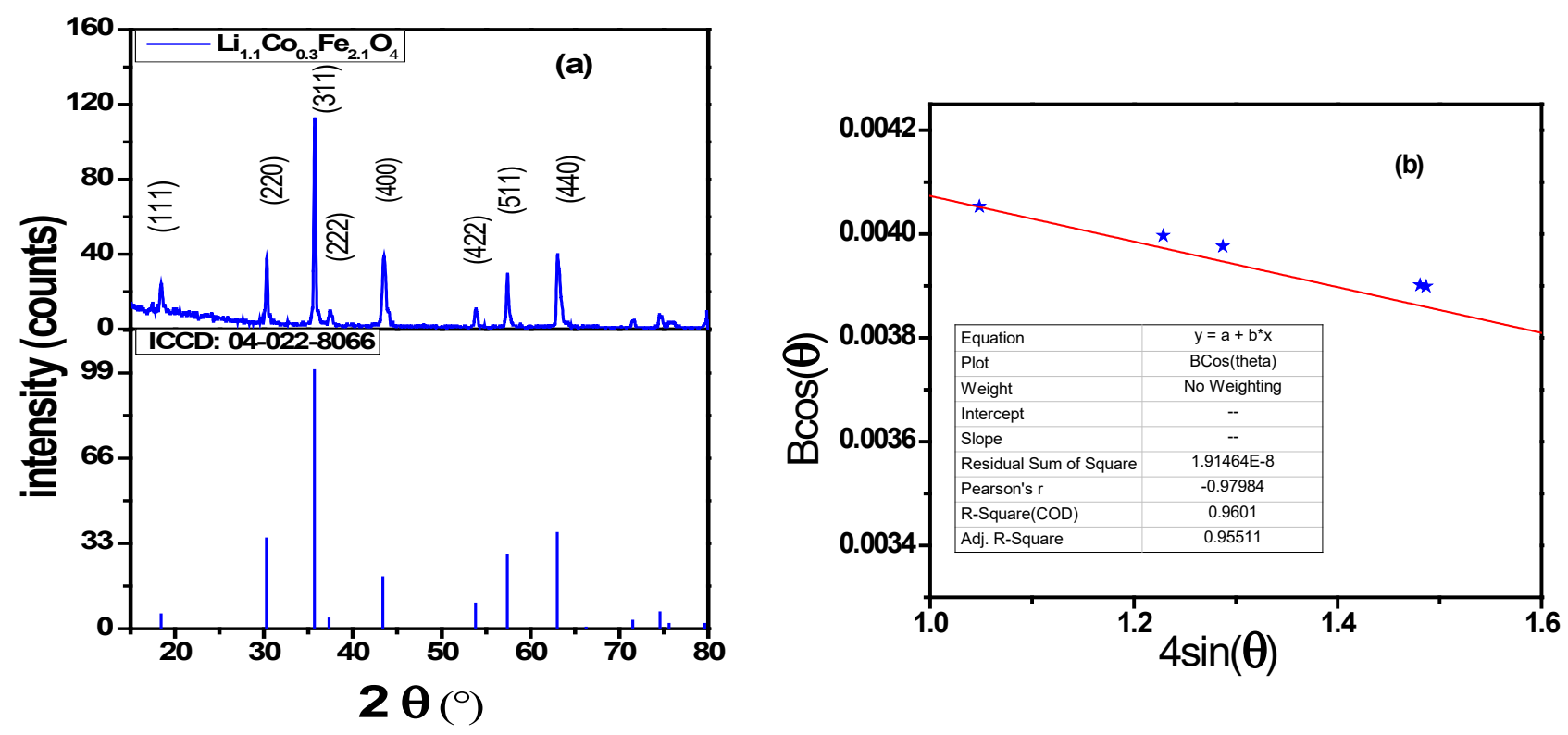

Fig. 2 :a-b The XRD diffraction pattern and The Williamson-Hall plot for $\mathrm{Li}_{1.1} \mathrm{Co}_{0.3} \mathrm{Fe}_{2.1} \mathrm{O}_{4}$ 
where $\beta$ is the FWHM of XRD peak; $\theta$ is the Bragg angle; $K$ is the dimensionless shape factor $(\mathrm{K}=0.9) ; \lambda$ is the wavelength of $\mathrm{CuK} \alpha$ radiation $(\lambda=1.5406)$. Figure $2 \mathrm{~b}$ shows the fitting plots of $\beta \cos \theta$ versus $4 \sin \theta$, and the $\varepsilon$ is determined from the slope. The calculated values of $\varepsilon$ and DXRD are listed in Table 1. The strain is considered to be uniform in all the crystallographic directions. The W-H plot for the investigated sample shows the negative value of the strain indicates the compressive nature of it which leads to lattice shrinkage.

The dislocation density $\delta$, represents the total defects in the sample. It is defined as the length of dislocation lines per unit volume of the crystal and it is calculated using the following equation $[23]$ :

$$
\delta=\frac{1}{D^{2}}
$$

Other important parameters that reveal the crystallization of the sample crystals are the distortion parameter (g), inter-chain distance (r), and theoretical density (Dx). These parameters can be calculated from XRD data by using the following equations [24][25];

$$
g=\frac{\beta}{\tan \theta} \quad \text { (5) } \quad r=\frac{5 \lambda}{8 \sin \theta} \quad \text { (6) } \quad D x=\frac{Z M}{N V}
$$

where $\mathrm{Z}(8)$ is the number of molecules per unit cell, $\mathrm{M}$ is the molecular weight, $\mathrm{N}$ is Avogadro's number and $\mathrm{V}$ is the unit cell volume. All the calculated parameters are tabulated in the Table.

Table 1 Experimental lattice parameter (a), Crystallite size (D), dislocation density ( $\delta$ ), Distortion parameter (g), micro strain $(\varepsilon)$, Inter chain distance (r), Unit cell volume (V) and X-ray density (Dx) .

\begin{tabular}{lcccccccc}
\hline Sample & (a) ${ }^{\circ} \mathrm{A}$ & $\mathrm{D}(\mathrm{nm})$ & $\delta(\mathrm{nm})^{-2}$ & $(\mathrm{~g})$ & $\varepsilon 10^{-5}$ & $\mathrm{r}(\mathrm{nm})$ & $\mathrm{V}(\mathrm{nm})^{3}$ & $\mathrm{Dx}\left(\mathrm{g}_{\mathrm{m}} . \mathrm{cm}-{ }^{3}\right)$ \\
\hline $\mathrm{Li}_{1.1} \mathrm{Co}_{0.3} \mathrm{Fe}_{2.1} \mathrm{O}_{4}$ & 8.324 & 30.7 & 0.001 & 0.013 & 43 & 0.313 & 0.576 & 4.758 \\
\hline
\end{tabular}

The prepared sample is of high quality with good crystallinity and fine crystallite size as confirmed from the calculated parameters in the Table.

Fig. 3a-b illustrates the high- resolution transmission electron micrographs (HRTEM) for $\mathrm{Li}_{1.1} \mathrm{Co}_{0.3} \mathrm{Fe}_{2.1} \mathrm{O}_{4}$ sample, inset (a) the selected area electron diffraction patterns (SAED) and inset (b) histogram of the size distribution. 

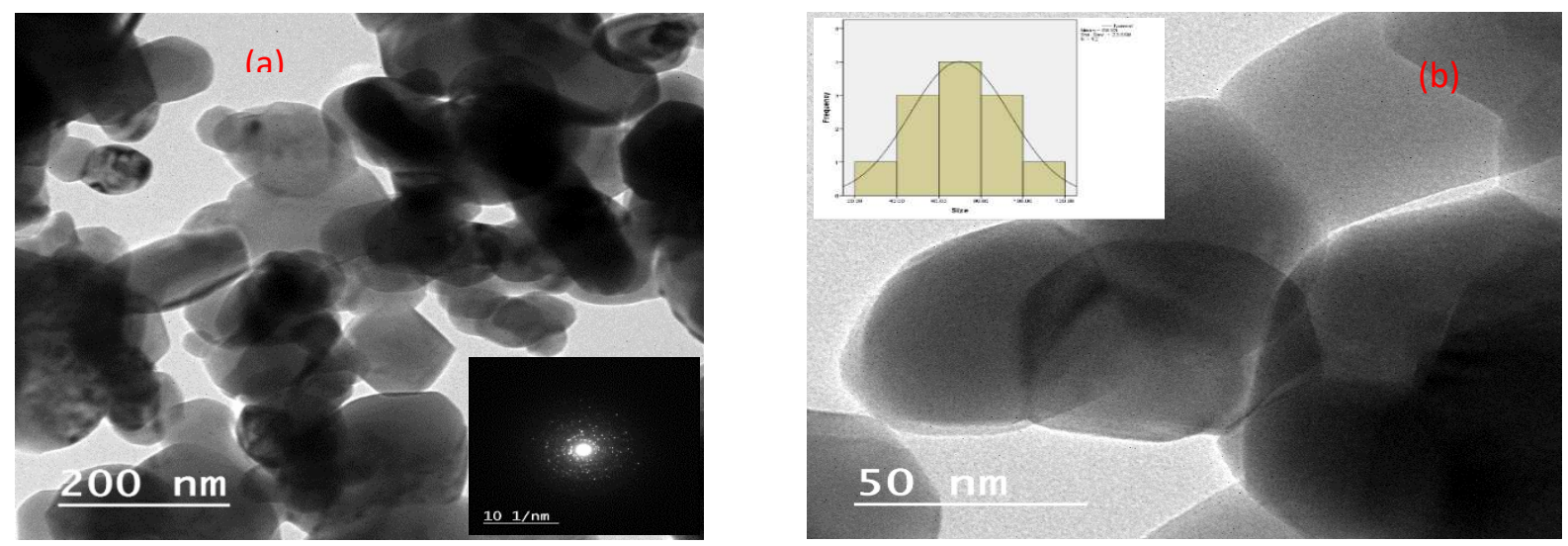

Fig. 3 a-b HRTEM with the selected area electron diffraction patterns (SAED) and histogram represents the size distribution for the $\mathrm{Li}_{1.1} \mathrm{Co}_{0.3} \mathrm{Fe}_{2.1} \mathrm{O}_{4}$.

The shape of $\mathrm{Li}_{1.1} \mathrm{Co}_{0.3} \mathrm{Fe}_{2.1} \mathrm{O}_{4}$ nanoparticle is roughly spherical and highly agglomerated due to the magnetic nature of the sample. The selected area electron diffraction (SAED) consists of concentric rings with spots over the rings. This characteristic specifies that the sample is good nanocrystalline in nature [26]. The rings with a dotty pattern in SAED ratify the varied size distribution of the nano ferrite sample. The inset in Fig. 3b shows the size distribution of the sample and the mean particle size is $70 \mathrm{~nm}$.

Atomic force microscopy (AFM) is a crucial tool to scrutinize the surface topography of the material. Fig. 4 shows the 2D - AFM image of the $\mathrm{Li}_{1.1} \mathrm{Co}_{0.3} \mathrm{Fe}_{2.1} \mathrm{O}_{4}$ nano ferrite particle. The images show that $\mathrm{Li}_{1.1} \mathrm{Co}_{0.3} \mathrm{Fe}_{2.1} \mathrm{O}_{4}$ exhibits waviness surface texture. The hill region is comparatively rough compared to the valley region. In other words, the typical roughness is the same for surfaces with roughness profiles completely different, because it takes into consideration the average profile of heights only. For this reason, additional sophisticated parameters can be clarified to fully describe a surface when more significant data is required.

The profile peak height $\left(\mathrm{R}_{\mathrm{p}}\right)$ is the measure of the highest peak around the surface profile from the baseline. Similarly, the valley depth $\left(\mathrm{R}_{\mathrm{v}}\right)$ is the measure of the deepest valley across the surface profile analyzed from the baseline. Consequently, the maximum height of the profile ( $\mathrm{R}$ ) can be identified as the vertical distance between the minimum valley and the maximum peak as shown in Fig. 4c.

$$
\mathrm{R}_{\mathrm{T}}=\mathrm{R}_{\mathrm{p}}+\mathrm{R}_{\mathrm{v}}
$$


Table 2 show Maximum Profile Valley Depth $\mathrm{R}_{\mathrm{v}}$, Maximum Profile Peak Height $\mathrm{R}_{\mathrm{p}}$, Maximum Height of the Profile $\mathrm{R}_{\mathrm{T}}$ average roughness $\mathrm{R}_{\mathrm{a}}$, root mean square roughness $\mathrm{R}_{\mathrm{q}}$, , skewness of the line $\mathrm{R}_{\mathrm{sk}}$, and kurtosis of the line $\mathrm{R}_{\mathrm{k}}$

\begin{tabular}{lccccccc}
\hline Sample & Rv nm & Rp nm & RT nm & Ra nm & Rq nm & Rsk & Rku \\
\hline $\mathrm{Li}_{1.1} \mathrm{Co}_{0.3} \mathrm{Fe}_{2.1} \mathrm{O}_{4}$ & 5.03 & 6.73 & 11.8 & 0.707 & 1.06 & 1.0 & 5.50 \\
\hline
\end{tabular}

The roughness parameters are estimated by analyzing the topography scans of the sample's surface and the obtained data is tabulated in Table 2. As shown from the Table, the surface profile parameters include average roughness (Ra), root mean square roughness $(\mathrm{Rq})$, maximum peak to valley height (Rt), skewness of the line (Rsk), kurtosis of the line (Rku). These parameters are important for obtaining specified data, like a scratch or an unusual crack on the material.
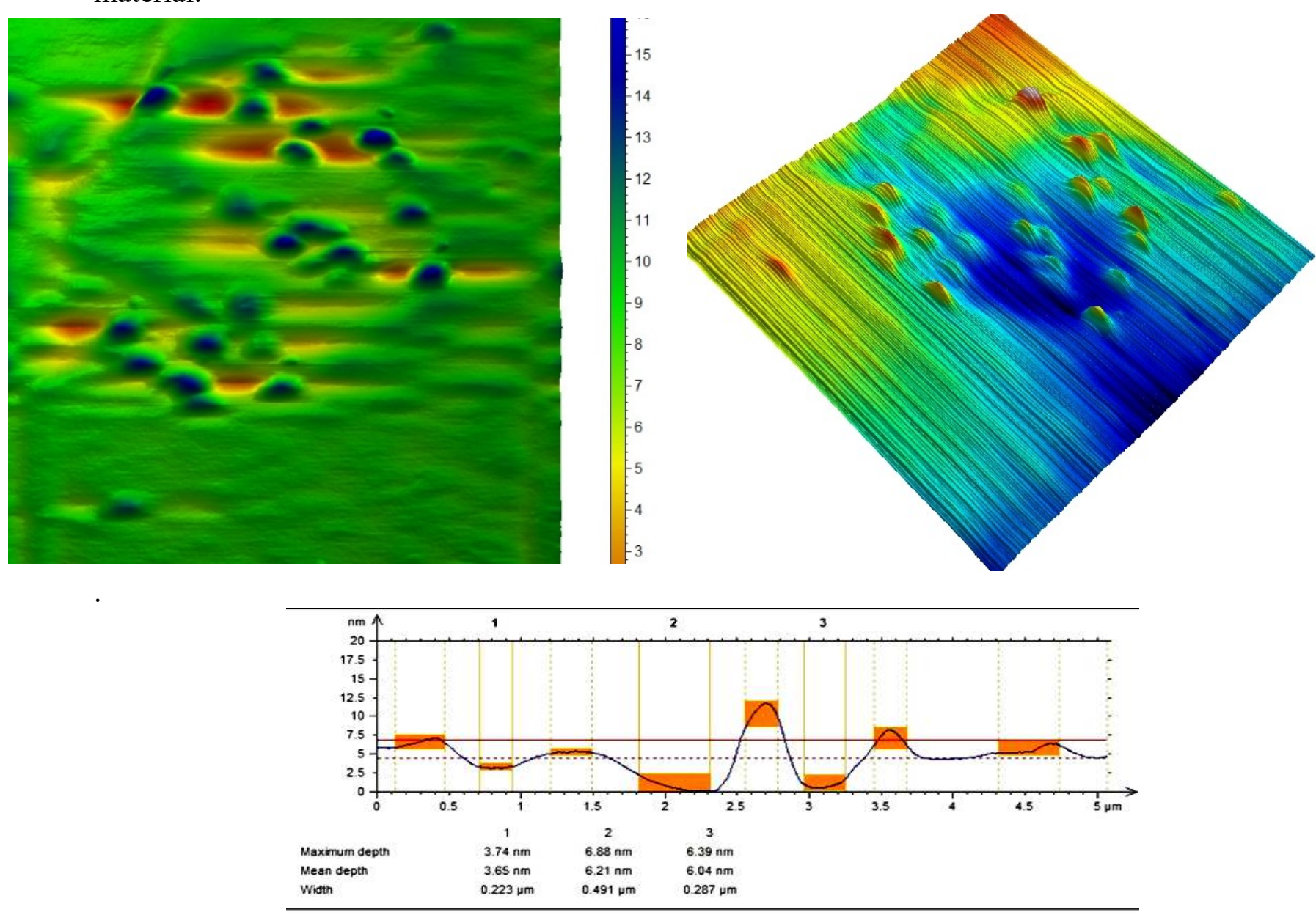

Fig. 4 a-c AFM image of the $\mathrm{Li}_{1.1} \mathrm{Co}_{0.3} \mathrm{Fe}_{2.1} \mathrm{O}_{4}$ nano ferrite sample. 
Roughness skewness $\left(\mathrm{R}_{\mathrm{sk}}\right)$ is used to measure the symmetry and is more sensitive to occasional deep valleys or high peaks. Usually, $R_{s k}$ is used to distinguish two profiles of the same $R_{a}$ or $R_{q}$ values but of different shapes.

Roughness kurtosis $\left(\mathrm{R}_{\mathrm{ku}}\right)$ is utilized to estimate the distribution of the spikes above and below the mean plane. For spiky surfaces, $R_{k u}>3$; for bumpy surfaces, $R_{k u}<3$. According to the value of $\mathrm{R}_{k u}$ the $\mathrm{Li}_{1.1} \mathrm{Co}_{0.3} \mathrm{Fe}_{2.1} \mathrm{O}_{4}$ has a spiky surface $\left(\mathrm{R}_{k u}=5.50\right)$.

Finally, roughness is a very significant parameter for numerous applications. The characterization of materials through their roughness allows one to attain data on the efficiency of samples in many application areas. The height and spacing parameters associated with roughness are essential to achieve the efficiency of $\mathrm{Li}_{1.1} \mathrm{Co}_{0.3} \mathrm{Fe}_{2.1} \mathrm{O}_{4}$ to be used in microbatteries, smart mirrors, gas sensors, and other applications.

The adsorption of molecules on surfaces as a function of the relative pressures $(\mathrm{P} / \mathrm{Po})$ of the adsorbate is elucidated by Brunauer, Emmett, and Teller theory.
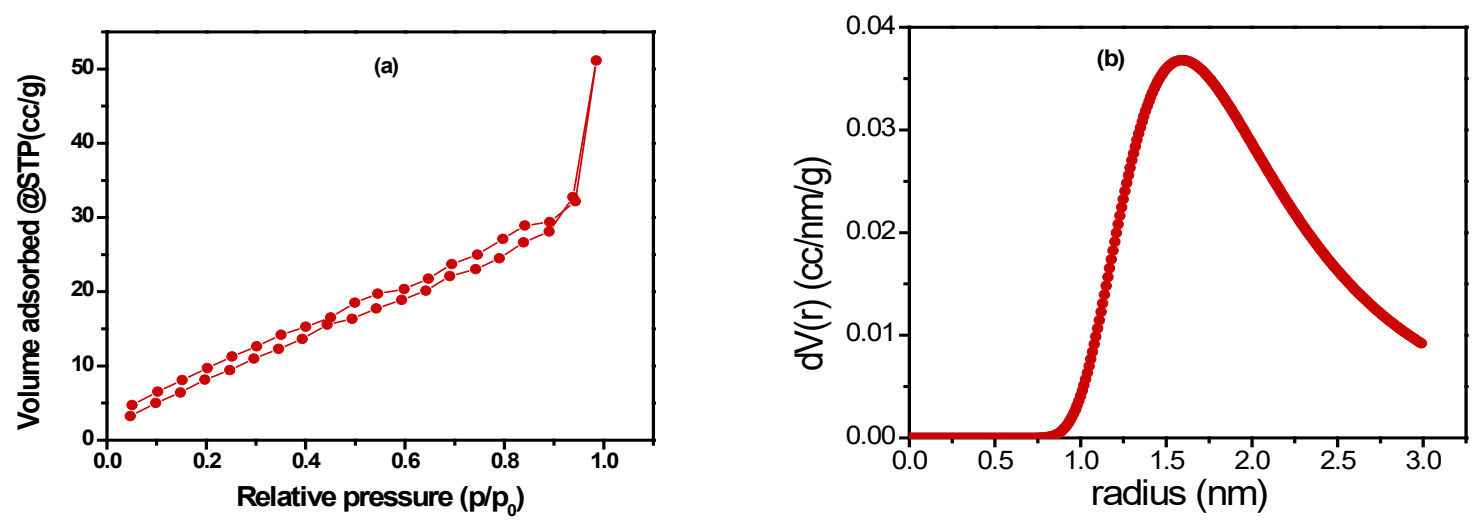

Fig. 5 a-b Type of sorption isotherms and pores distribution of $\mathrm{Li}_{1.1} \mathrm{Co}_{0.3} \mathrm{Fe}_{2.1} \mathrm{O}_{4}$.

Figure 5a illustrates the adsorption/desorption isotherm of nitrogen at $77 \mathrm{~K}$ for $\mathrm{Li}_{1.1} \mathrm{Co}_{0.3} \mathrm{Fe}_{2.1} \mathrm{O}_{4}$ ferrite nanoparticles. As shown from the plot that the desorption branch does not follow the 
adsorption branch. It forms an obvious hysteresis loop. This loop is due to the amount of adsorbed along the desorption branch and the adsorption branch is quite different. The sorption isotherm is categorized as type IV and the hysteresis loop is of type H1. This agrees well with the IUPAC (International Union of Pure and Applied Chemistry) classification.

The distribution of pore radius versus pore volume of the studied sample is shown in Fig. $5 \mathrm{~b}$. Adsorption is dependent on the surface area, pore sizes as well as pore volume. The BET surface area of $\mathrm{Li}_{1.1} \mathrm{Co}_{0.3} \mathrm{Fe}_{2.1} \mathrm{O}_{4}$ is about $127.14 \mathrm{~m}^{2} / \mathrm{g}$. The pore volume and pore sizes are $0.0436 \mathrm{~cm}^{3} / \mathrm{g}$ and $2.034 \mathrm{~nm}$ respectively. According to the value of the pore size, the investigated sample can be classified as mesoporous materials [27]. In mesoporous materials, the sorption efficiency depends on two issues the first one is fluid wall interaction strength. The second is the attractive interactions between the fluid molecules. Consequently, multilayer adsorption and capillary condensation can occur in the pore.

Measurement of magnetization at room temperature for $\mathrm{Li}_{1.1} \mathrm{Co}_{0.3} \mathrm{Fe}_{2.1} \mathrm{O}_{4}$ nanocrystalline spinel powder is carried out using the VSM technique. Figure $6 a-b$ illustrates the magnetization versus external magnetic field $(\mathrm{M}-\mathrm{H})$ hysteresis loop and the fitted Langevin curve. The experimental $\mathrm{M}$ versus $\mathrm{H}$ loop is determined with an external applied magnetic field ranging between -20 and +20 kOe. The saturation magnetization value that corresponds to $20 \mathrm{kOe}$ is $39.898 \mathrm{emu} / \mathrm{g}$. The saturation magnetization (Ms) of $\mathrm{Li}_{1.1} \mathrm{Co}_{0.3} \mathrm{Fe}_{2.1} \mathrm{O}_{4}$ nanoparticle also can be detected by an approximation of Stoner-Wohlfarth theory by extrapolating the plot of magnetization versus $1 / \mathrm{H}^{2}$ to approach zero [28-30]. This theory is applied for non-interacting particles as confirm from squareness values in the Tables. In this way, the Ms value is equal to $40.10 \mathrm{emu} / \mathrm{g}$. The obtained value is very comparable to the experimental value signifying that an applied field of $\pm 20 \mathrm{kOe}$ is appropriate to saturate the investigated samples.

The $\mathrm{Li}^{1+}$ ion is a nonmagnetic cation $(0 \mu \mathrm{B})$ that does not respond to the magnetization of the sub-lattice. Consequently, it does not impart to the net magnetic moment. $\mathrm{Li}_{1.1} \mathrm{Co}_{0.3} \mathrm{Fe}_{2.1} \mathrm{O}_{4}$ ferrite has a partially inverse structure so most of the lithium ions occupy octahedral sites (B-sites) where as $\mathrm{Fe}^{3+}(5 \mu \mathrm{B})$ and $\mathrm{Co}^{2+}(3 \mu \mathrm{B})$ ions are distributed on both octahedral (B-sites) and tetrahedral sites (A-sites) [31,32]. Moreover, cobalt reveals an irregular trend when incorporated in Li ferrites. 
The magnetization trend of the ferrite samples is due to the contributions of the magnetic moments from $\mathrm{Fe}^{3+}$ and $\mathrm{Co}^{2+}$ at B-sites [33,34]. Neel's phenomenological model is applied to elucidate the magnetic parameters in $\mathrm{LiCoFeO}_{4}$ ferrites nanoparticles.

The obtained value of saturation magnetization is lower than that found in previous studies of $\mathrm{Li}_{0.5} \mathrm{Fe}_{2.5} \mathrm{O}_{4}$ nanoparticles [35]. The less magnetization of the samples is due to the fact that the magnetization of A-sublattice becomes much diluted and the A-B exchange interactions become weaker or comparable with the B-B exchange interactions. Consequently, the canted spins and the Yafet-Kittel (Y-K) angle are increased [36].

Additionally, it can be also owed to the formation of an inactive magnetic layer $[37,38]$ and the disordered cation distribution [39].
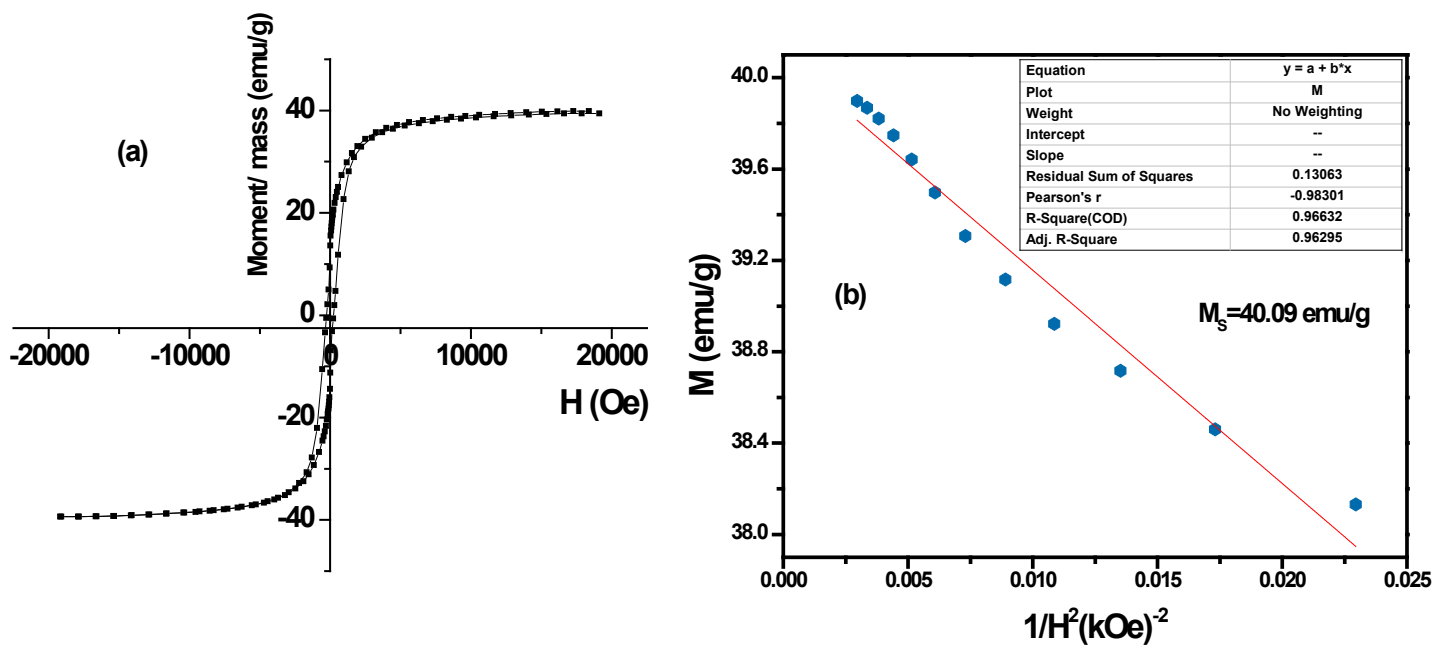

Fig. 6 a-b VSM and fitting plot between $\mathrm{M}$ versus $1 / \mathrm{H}^{2}$ for $\mathrm{Li}_{1.1} \mathrm{Co}_{0.3} \mathrm{Fe}_{2.1} \mathrm{O}_{4}$ sample .

From the hysteresis loops, the coercivity $\left(\mathrm{H}_{\mathrm{C}}\right)$, saturation magnetization $\left(\mathrm{Ms}_{\mathrm{s}}\right)$, remnant magnetization $\left(\mathrm{M}_{\mathrm{r}}\right)$, squareness $\left(\mathrm{M}_{\mathrm{r}} / \mathrm{M}_{\mathrm{s}}\right)$, exchange bias [40], and magnetic moment $\left(\mathrm{n}_{B}\right)$ [41] are calculated and tabulated in Table 3.

Coercivity is often considered an extrinsic property of materials. It is sensitive to defects as grain boundaries, and dislocations. The value of the squareness ratio $\left(\mathrm{M}_{\mathrm{r}} / \mathrm{M}_{\mathrm{s}}\right)$ is an indication of the soft character of the nanoparticles and its value varies from 0 to 1 [42]. In the present case, the $\mathrm{Li}_{1.1} \mathrm{Co}_{0.3} \mathrm{Fe}_{2.1} \mathrm{O}_{4}$ sample interacts magneto statically according to Stoner-Wolfarth model [46]. 
The anisotropy constant is determined from the Stoner-Wohlfarth equation as follows

$$
K=\frac{H_{C} \times M_{S}}{0.96}
$$

Where $\mathrm{H}_{\mathrm{c}}$ is the coercivity, $\mathrm{M}_{\mathrm{s}}$ saturation magnetization and $\mathrm{K}$ is magnetic anisotropy constant. The weak anisotropy of the investigated samples is due to the non-collinearity (canting) of spins on their surface.

A noticeable shift of the loop is detected and is ascribed to exchange bias phenomena. The exchange bias field are detected from the following equation and tabulated in the Table.

$$
\mathrm{H}_{\text {exch }}=-\left(\mathrm{H}_{\text {left }}+\mathrm{H}_{\text {right }}\right) / 2
$$

This is referred to the existence of different spin configurations. In nanostructure sample, the magnetic structure of the core is different from that of the surface where spin frustration predominates $[47,48]$.

Table 3 Values of the saturation magnetization $\left(M_{s}\right)$, remanence magnetization $\left(M_{r}\right)$, the coercive field $\left(H_{c}\right), M-H$ loop area, Anisotropy Constant $(\mathrm{K})$, Squareness, magnetic moment $\left(\mathrm{n}_{\mathrm{B}}\right)$, and the exchange bias for $\mathrm{Li}_{1.1} \mathrm{Co}_{0.3} \mathrm{Fe}_{2.1} \mathrm{O}_{4}$.

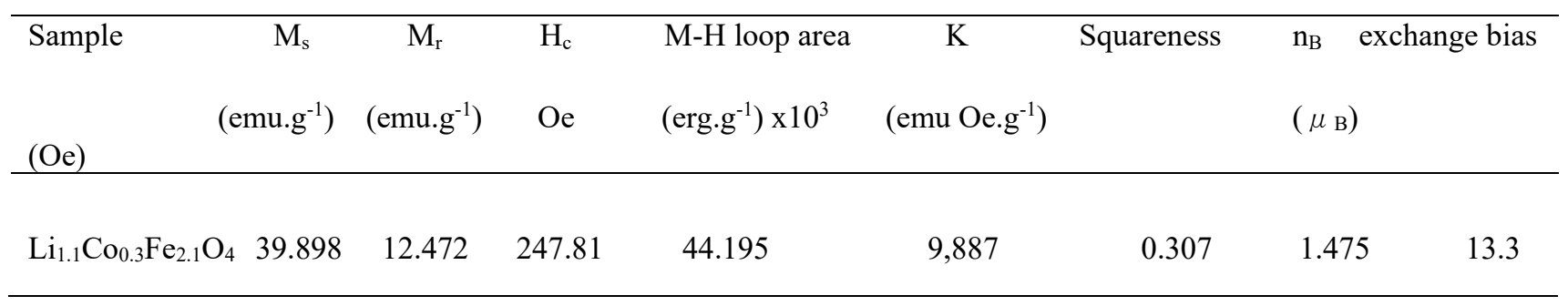

The Switching Field Distribution (SFD) for the materials is one of the significant criteria for magnetic recording. It has a high impact on high- density recording performance [49].

Fig. 7 shows the SFD value for the $\mathrm{Li}_{1.1} \mathrm{Co}_{0.3} \mathrm{Fe}_{2.1} \mathrm{O}_{4}$ as a function of coercivity. Here, the SFD value is calculated from eq. (11) as the ratio of the half-width of the peak in the derivative M-H and coercivity

$$
\mathrm{SFD}=\frac{\Delta \mathrm{H}}{\mathrm{Hc}}
$$

The derivative curve shows a double peak typical of a two - step reversal. Generally, the double peak characteristic in the derivative reveals the competition between exchange coupling and strong dipolar interactions. 
Tuning the dipolar field energy to a value of the same order as the exchange coupling energy leads to a double peak derivative whose first peak usually occurs before reaching zero field coming from the saturation field [50-52]. Therefore, in our sample, the dipolar interactions are more effective, which implies a strong reduction of the inter bump exchange coupling in our bump array.

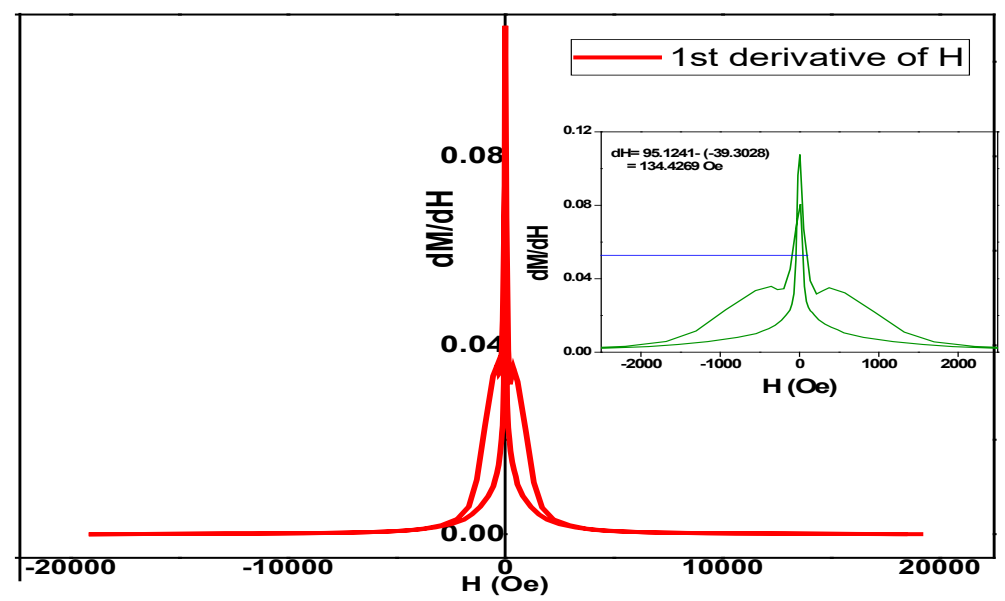

Fig. $7 \mathrm{SFD}$ value for the $\mathrm{Li}_{1.1} \mathrm{Co}_{0.3} \mathrm{Fe}_{2.1} \mathrm{O}_{4}$ as a function of coercivity.

From the above arguments, it is concluded that the small SFD value (0.544) of the investigated sample is due to an intrinsic magnetic nature such as uniformity of substitution and crystallinity as confirmed from XRD data.

The removal of $\mathrm{Pb}$ II heavy metal cations from an aqueous solution is detected through batch experiments using nano- $\mathrm{Li}_{1.1} \mathrm{Co}_{0.3} \mathrm{Fe}_{2.1} \mathrm{O}_{4}$ as an adsorbent. The interaction between adsorbent and adsorbate can be adjusted by experimental parameters as $\mathrm{pH}$ values [51]. The concentration of heavy metal nitrates is measured by the ICP technique. The removal efficiency of investigated sample is determined using Equations $(1,2)$ as mentioned in the experimental section.

Figure 8 illustrates the effect of $\mathrm{pH}$ on the adsorption efficiency of $\mathrm{Pb}^{2+}$ ions in the aqueous solution. The $\mathrm{pH}$ can influence the sorption capacity of $\mathrm{Pb}^{2+}$ ions by changing the surface charges of $\mathrm{Li}_{1.1} \mathrm{Co}_{0.3} \mathrm{Fe}_{2.1} \mathrm{O}_{4}$, the $\mathrm{Pb}^{2+}$ complex type, and the number of active sites available for the adsorption process [52]. 
The results indicate that $\mathrm{Pb}^{2+}$ removal increases to the maximum with increasing $\mathrm{pH}$ from 4 to 8 at room temperature $\left(30^{\circ} \mathrm{C}\right)$ as shown in Table (4). In the present study, the maximum efficiency of $\mathrm{Pb}^{2+}$ removal is about $99.82 \%$ at $\mathrm{pH}$ 8. This is elucidated in view of a competition between $\mathrm{H}^{+}$and $\mathrm{Pb}$ (II) ions to be adsorbed on $\mathrm{Li}_{1.1} \mathrm{Co}_{0.3} \mathrm{Fe}_{2.1} \mathrm{O}_{4}$. At lower $\mathrm{pH}$ values, $\mathrm{H}+$ ions are able to prevent a significant number of adsorption sites at $\mathrm{Li}_{1.1} \mathrm{Co}_{0.3} \mathrm{Fe}_{2.1} \mathrm{O}_{4}$ from the $\mathrm{Pb}^{2+}$ adsorption process [52]. While, at high $\mathrm{pH}$ values, the $\mathrm{H}+$ ions competition nearly vanishes and the positively charged $\mathrm{Pb}^{2+}$ and $\mathrm{Pb}(\mathrm{OH})^{+}$ions can be attached to the free binding sites, increasing the uptake of the $\mathrm{Pb}^{2+}$ ions [53].

Table 4 and Fig. (8) Effect of $\mathrm{pH}$ on the adsorption efficiency of $\mathrm{Pb}^{2+}$ ions.

\begin{tabular}{lcccc}
\hline Pollutant & $\mathrm{PH}$ & $\mathrm{C}_{\mathrm{i}}\left(\mathrm{mg} . \mathrm{L}^{-1}\right)$ & $\mathrm{C}_{\mathrm{e}}\left(\mathrm{mg} \cdot \mathrm{L}^{-1}\right)$ & $\eta \%$ \\
\hline $\mathrm{Pb}$ & 4 & 6.501 & 3.018 & 53.56 \\
& 5 & & 2.998 & 53.88 \\
& 6 & & 0.065 & 99.00 \\
& 7 & & 0.022 & 99.66 \\
& 8 & & 0.012 & 99.82 \\
\hline
\end{tabular}

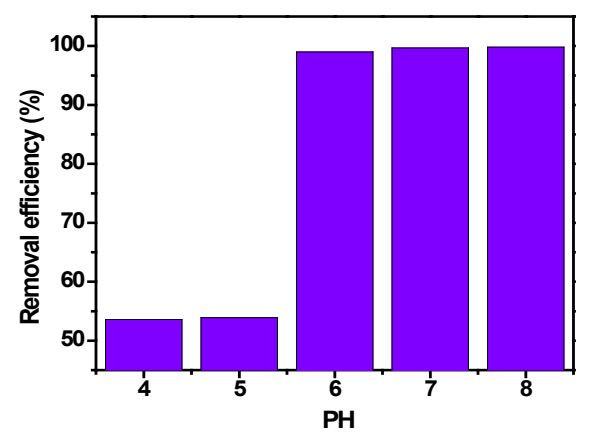

The most recurrently utilized models to designate the adsorption results are the Freundlich and Langmuir isotherms. In the case study, these models are applied to scrutinize the adsorption of the heavy metals on $\mathrm{Li}_{1.1} \mathrm{Co}_{0.3} \mathrm{Fe}_{2.1} \mathrm{O}_{4}$ at different $\mathrm{Pb}^{2+}$ ion concentrations. This study is carried out for equilibrium metal ion concentrations varying from 11.9351 to $0 \mathrm{mg} / \mathrm{L}$. The constants of the two models are calculated using the following relations and the results are presented in the inset of Fig. 9a-b. The Langmuir equation is given by [17]:

$$
\frac{C_{e}}{q_{e}}=\frac{1}{q_{m} K_{L}}+\frac{C_{e}}{q_{m}}
$$

While the Freundlich logarithmic form of equation is specified as [54]

$$
\operatorname{Ln} q_{e}=\operatorname{Ln} K_{f}+\frac{1}{n} \operatorname{Ln} C_{e}
$$

Where $C e$, equilibrium metal concentration $(\mathrm{mg} / \mathrm{L}), q_{m}$ and $K_{L}$ are the Langmuir constants accompanying with maximum adsorption capacity $(\mathrm{mg} / \mathrm{g})$, and the relative energy of adsorption 
(L/mg), respectively. $\mathrm{q}_{\mathrm{e}}$ is the equilibrium sorption capacity $(\mathrm{mg} / \mathrm{g}), \mathrm{K}_{\mathrm{F}}$ and $\mathrm{n}$ are Freundlich equilibrium constants.
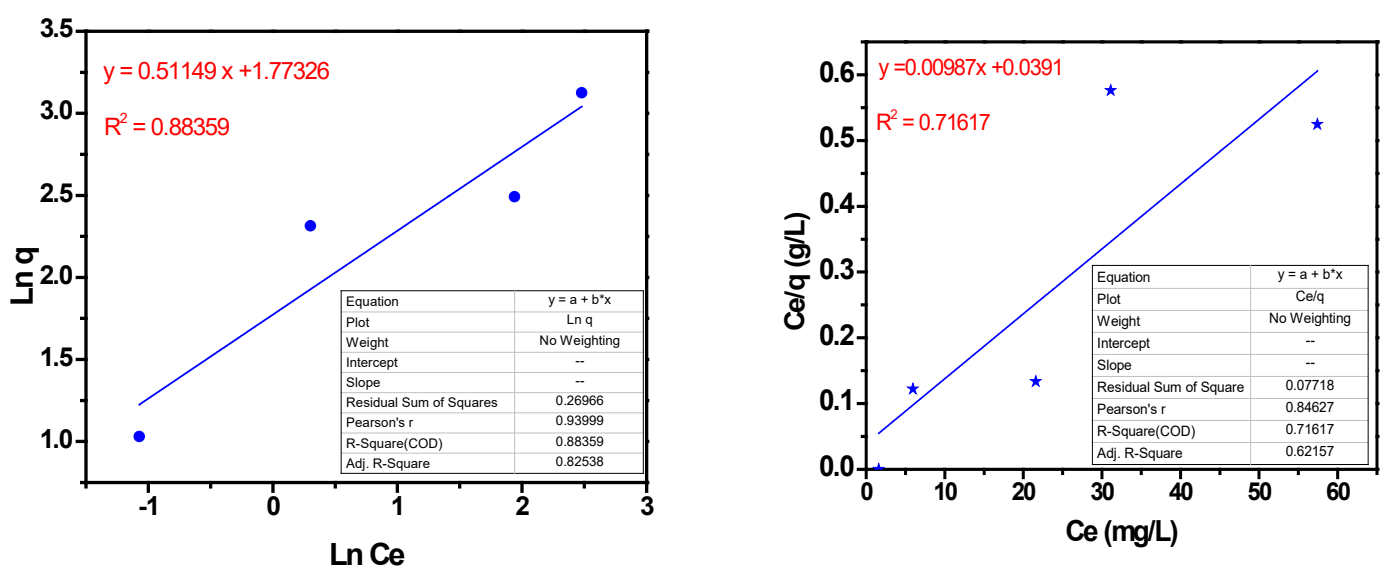

Fig. 9 a-b Linear fits of experimental data of the adsorption of $\mathrm{Pb}^{2+}$ onto $\mathrm{Li}_{1.1} \mathrm{Co}_{0.3} \mathrm{Fe}_{2.1} \mathrm{O}_{4}$ (a) Langmuir and (b) Freundlich sorption isotherms. The inset various constants of the two models.

It indicates that the experimental data fitted well to both isotherm models. The Langmuir model, considering a monolayer adsorption process of molecules on solid surfaces, gives a good model for the adsorption system. According to this model, see Eq. (12) and Fig. 9a, the maximum sorption capacity, $\mathrm{qm}$, is estimated as $102.04 \mathrm{mg} / \mathrm{g}$. The Langmuir constant, $\mathrm{K}_{\mathrm{L}}$, equals 0.2503 $\mathrm{L} / \mathrm{mg}$ which designates high sorption energy between $\mathrm{Pb}$ II and $\mathrm{Li}{ }_{1.1} \mathrm{Co}_{0.3} \mathrm{Fe}_{2.1} \mathrm{O}_{4}$. The electrostatic nature of bonding between $\mathrm{Pb}^{2+}$ and $\mathrm{Li}_{1.1} \mathrm{Co}_{0.3} \mathrm{Fe}_{2.1} \mathrm{O}_{4}$ nano ferrite sample is the main reason for the observed high sorption of $\mathrm{Pb}^{2+}$ ions on $\mathrm{Li}_{1.1} \mathrm{Co}_{0.3} \mathrm{Fe}_{2.1} \mathrm{O}_{4}$.

Furthermore, the parameters $\left(\mathrm{K}_{\mathrm{f}}\right.$ and $\left.1 / \mathrm{n}\right)$ calculated from the intercept and slope of this Fig. $9 \mathrm{~b}$, respectively are given in the inset of the figure. The small value of $1 / \mathrm{n}$ (less than 1 ) for the adsorption of lead $\mathrm{Pb}^{2+}$ on the $\mathrm{Li}_{1.1} \mathrm{Co}_{.3} \mathrm{Fe}_{2.1} \mathrm{O}_{4}$ showing that the adsorption process is favorable.

\section{Conclusion}

$\mathrm{Li}_{1.1} \mathrm{Co}_{.3} \mathrm{Fe}_{2.1} \mathrm{O}_{4}$ nano sample was prepared in single phase cubic spinel with space group (Fd$3 \mathrm{~m})$. XRD assure that the sample was prepared in nano scale with crystallite size $30 \mathrm{~nm}$. The shape of nanoparticles is roughly spherical and highly agglomerated. $M_{r} / M_{s}$ ratio assure the sample $\mathrm{Li}_{1.1} \mathrm{Co}_{0.3} \mathrm{Fe}_{2.1} \mathrm{O}_{4}$ has magneto static interaction. The sample has a weak ferrimagnetic 
behavior with Curie temperature near $715 \mathrm{~K} . V$. The adsorption data are fitted to the Freundlich and Langmuir isotherm models. The best fitting is obtained by utilized the Freundlich model for $\mathrm{Pb}^{+2}$ metal i.e. $\mathrm{PbII}$ with $\mathrm{R}^{2}$ value 0.8835 .

\section{Declarations}

Funding

This research was funded by Academy of Scientific Research \& Technology (ASRT) (No. 6643)

\section{Conflict of interest}

The authors declare that they have no conflict of interest.

Availability of data and material

Not applicable

\section{ASRT Acknowledgments}

The authors are appreciative the Academy of Scientific Research \& Technology (ASRT), Egypt funding project No. 6643 (Science Up) which made facilities available at the sustainable Central Lab, Faculty of Science -Cairo University.

\section{References}

1. R. Cheruku, G. Govindaraj, and L. Vijayan, Mater. Chem. Phys. 146, 389 (2014).

2. Y.-P. Fu and S.-H. Hu, Ceram. Int. 36, 1311 (2010).

3. H. Zeng, T. Tao, Y. Wu, W. Qi, C. Kuang, S. Zhou, and Y. Chen, RSC Adv. 4, 23145 (2014).

4. N. Rezlescu, C. Doroftei, E. Rezlescu, and P. D. Popa, Sensors Actuators B Chem. 133, 420 (2008).

5. H. Zhu, S. Zhang, Y.-X. Huang, L. Wu, and S. Sun, Nano Lett. 13, 2947 (2013).

6. R. Yadav, M. K. Yadav, and N. K. Singh, Int. J. Electrochem. Sci 8, 6321 (2013).

7. X. Zhao, Y. Fu, J. Wang, Y. Xu, J.-H. Tian, and R. Yang, Electrochim. Acta 201, 172 (2016).

8. C. H. Kim, Y. Myung, Y. J. Cho, H. S. Kim, S.-H. Park, J. Park, J.-Y. Kim, and B. Kim, J. Phys. Chem. C 113, 7085 (2009).

9. Y. Wang, D. Su, A. Ung, J. Ahn, and G. Wang, Nanotechnology 23, 55402 (2012).

10. Z. Zhang, Y. Wang, M. Zhang, Q. Tan, X. Lv, Z. Zhong, and F. Su, J. Mater. Chem. A 1, 7444 (2013). 
11. P. He, K. Yang, W. Wang, F. Dong, L. Du, and Y. Deng, Russ. J. Electrochem. 49, 359 (2013).

12. L. Lv, Q. Xu, R. Ding, L. Qi, and H. Wang, Mater. Lett. 111, 35 (2013).

13. G. A. Sawatzky, F. Van Der Woude, and A. H. Morrish, J. Appl. Phys. 39, 1204 (1968).

14. V. Neburchilov, H. Wang, J. J. Martin, and W. Qu, J. Power Sources 195, 1271 (2010).

15. E. Rios, J.-L. Gautier, G. Poillerat, and P. Chartier, Electrochim. Acta 44, 1491 (1998).

16. E. E. Ateia, M. K. Abdelmaksoud, and H. Ismail, J. Mater. Sci. Mater. Electron. 1 (2021).

17. E. E. Ateia, R. Ramadan, and A. S. Shafaay, Appl. Phys. A 126, 1 (2020)..

18. R. Ramadan, S. I. El-Dek, and M. M. Arman, Appl. Phys. A 126, 1 (2020).

19. C. Singh, , E. E. Ateia, S. Bindra Narang, M. Farag, J. Singh, D.E. El-Nashar, Ceramic International, 47,5 (2021)

20. K. Tanida and T. Kitamura, Tohoku Daigaku Senko Seiren Kenkyusho Iho 40, 71 (1984).

21. S. K. Gurav, S. E. Shirsath, R. H. Kadam, S. M. Patange, K. S. Lohar, and D. R. Mane, Mater. Res. Bull. 48, 3530 (2013).

22. V. D. Mote, Y. Purushotham, and B. N. Dole, J. Theor. Appl. Phys. 6, 1 (2012).

23. M. A. Amer, A. Matsuda, G. Kawamura, R. El-Shater, T. Meaz, and F. Fakhry, J. Alloys Compd. 735, 975 (2018).

24. E. E. Ateia, H. Ismail, H. Elshimy, and M. K. Abdelmaksoud, J. Inorg. Organomet. Polym. Mater. 1 (2021).

25. M. A. Amer, T. M. Meaz, S. S. Attalah, and A. I. Ghoneim, J. Alloys Compd. 654, 45 (2016).

26. S. L. Reddy, T. R. Reddy, N. Roy, R. Philip, O. A. Montero, T. Endo, and R. L. Frost, Spectrochim. Acta Part A Mol. Biomol. Spectrosc. 127, 361 (2014).

27. R. Schmidt, E. W. Hansen, M. Stoecker, D. Akporiaye, and O. H. Ellestad, J. Am. Chem. Soc. 117, 4049 (1995).

28. A. Baykal, S. Esir, A. Demir, and S. Güner, Ceram. Int. 41, 231 (2015).

29. M. A. Almessiere, Y. Slimani, and A. Baykal, Ceram. Int. 44, 9000 (2018).

30. S. Güner, M. Amir, M. Geleri, M. Sertkol, and A. Baykal, Ceram. Int. 41, 10915 (2015).

31. A. Goldman, (n.d.).

32. I. Soibam, S. Phanjoubam, and C. Prakash, J. Magn. Magn. Mater. 321, 2779 (2009).

33. I. Soibam, S. Phanjoubam, and C. Prakash, J. Alloys Compd. 475, 328 (2009).

34. S. Ouaissa, A. Benyoussef, G. S. Abo, M. Ouaissa, and M. Hafid, Phys. Procedia 75, 792 (2015). 
35. R. P. Patil, S. B. Patil, B. V Jadhav, S. D. Delekar, and P. P. Hankare, J. Magn. Magn. Mater. 401, 870 (2016).

36. R. Topkaya, A. Baykal, and A. Demir, J. Nanoparticle Res. 15, 1 (2013).

37. S. Rasheed, R. A. Khan, F. Shah, B. Ismail, J. Nisar, S. M. Shah, A. Rahim, and A. R. Khan, J. Magn. Magn. Mater. 471, 236 (2019).

38. M. D. D. HOSSAIN, (2015).

39. T. Zeeshan, S. Anjum, S. Waseem, M. Riaz, and R. Zia, Ceram. Int. 46, 3935 (2020).

40. C. Vázquez-Vázquez, M. A. López-Quintela, M. C. Buján-Núñez, and J. Rivas, J. Nanoparticle Res. 13, 1663 (2011).

41. S. Panchal, S. Raghuvanshi, K. Gehlot, F. Mazaleyrat, and S. N. Kane, AIP Adv. 6, 55930 (2016).

42. U. Kurtan, R. Topkaya, A. Baykal, and M. S. Toprak, Ceram. Int. 39, 6551 (2013).

43. B. K. Rai, L. Wang, S. R. Mishra, V. V Nguyen, and J. P. Liu, J. Nanosci. Nanotechnol. 14, 5272 (2014).

44. G.-Y. Kim, J.-H. Jeon, M.-H. Kim, D. Suvorov, and S.-Y. Choi, Met. Mater. Int. 19, 1209 (2013).

45. S. Chakrabarty, A. Dutta, and M. Pal, J. Alloys Compd. 625, 216 (2015).

46. E. E. Ateia and F. S. Soliman, Mater. Sci. Eng. B 244, 29 (2019).

47. S. R. Naik, A. V Salker, S. M. Yusuf, and S. S. Meena, J. Alloys Compd. 566, 54 (2013).

48. K. Kamazawa, Y. Tsunoda, H. Kadowaki, and K. Kohn, Phys. Rev. B 68, 24412 (2003).

49. O. Hellwig, A. Berger, T. Thomson, E. Dobisz, Z. Z. Bandic, H. Yang, D. S. Kercher, and E. E. Fullerton, Appl. Phys. Lett. 90, 162516 (2007).

50. T. Hauet, L. Piraux, S. K. Srivastava, V. A. Antohe, D. Lacour, M. Hehn, F. Montaigne, J. Schwenk, M. A. Marioni, and H. J. Hug, Phys. Rev. B 89, 174421 (2014).

51. O. E. A. Salam, N. A. Reiad, and M. M. ElShafei, J. Adv. Res. 2, 297 (2011).

52. M. Horsfall Jnr and A. I. Spiff, Electron. J. Biotechnol. 7, 14 (2004).

53. H. Liu, Mechanisms of the Oxidation of Lead (II) Solid Phases by Chlorine and Its Relationships with Colloidal Lead Release (University of Washington, 2010). 


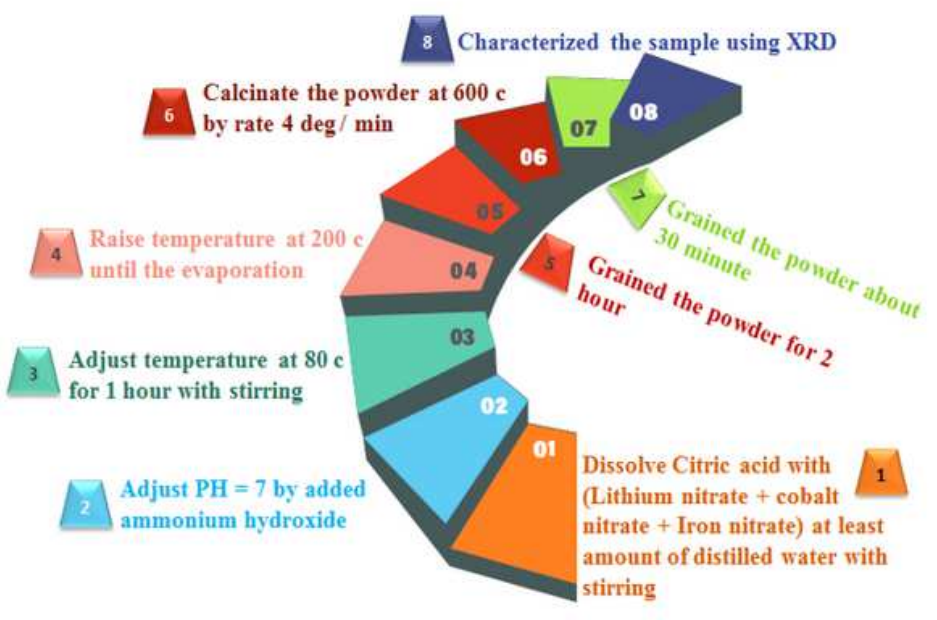

(a)

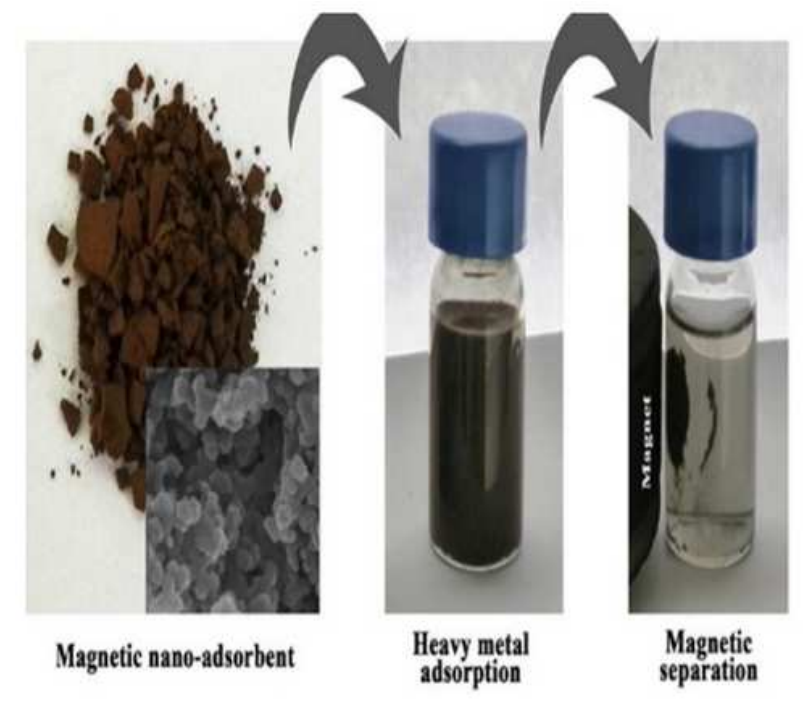

(b)

\section{Figure 1}

a-b Flowchart for the synthetic scheme and the recovery of Li1.1Co0.3Fe2.104 from water by a small magnet
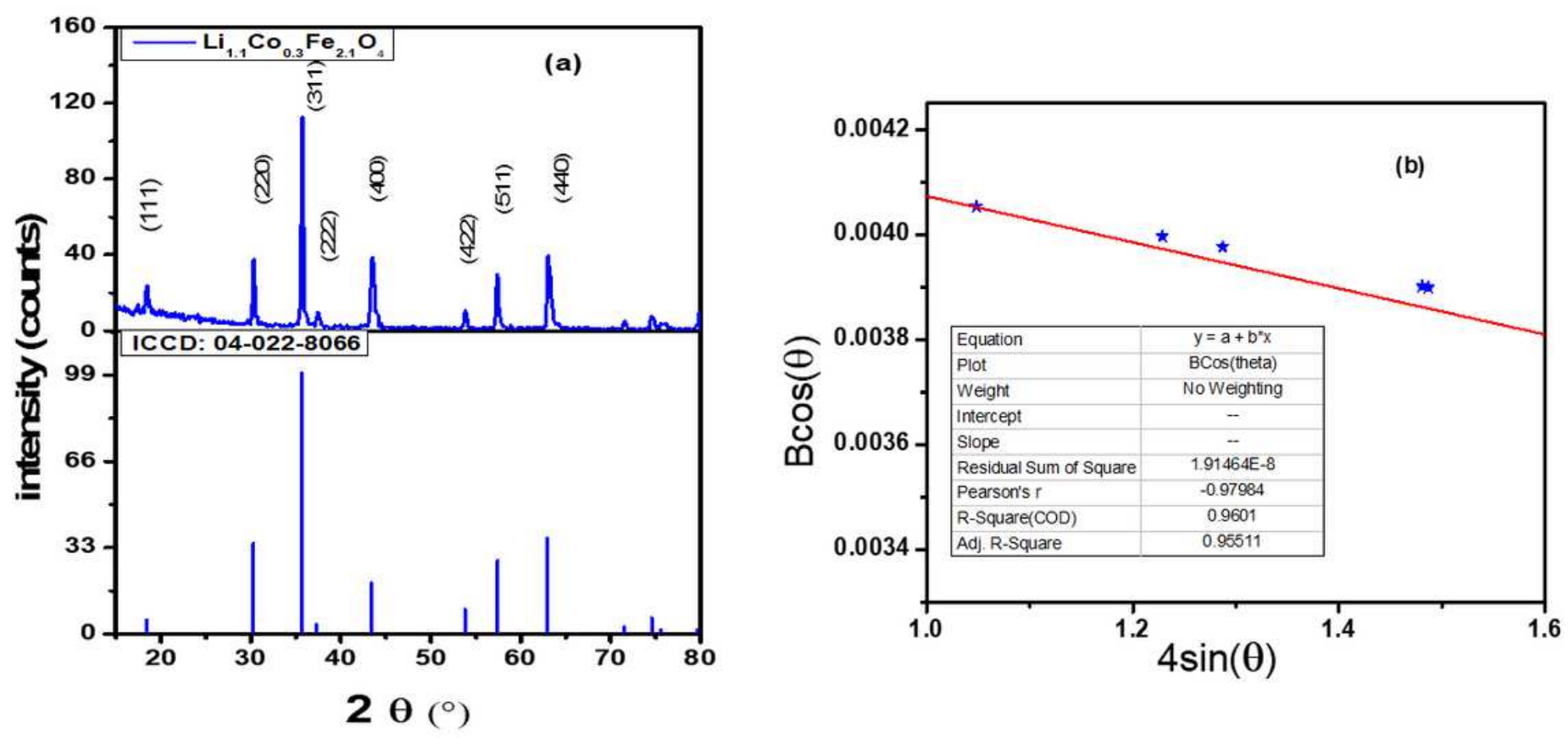

Figure 2

a-b The XRD diffraction pattern and The Williamson-Hall plot for Li1.1Co0.3Fe2.104 

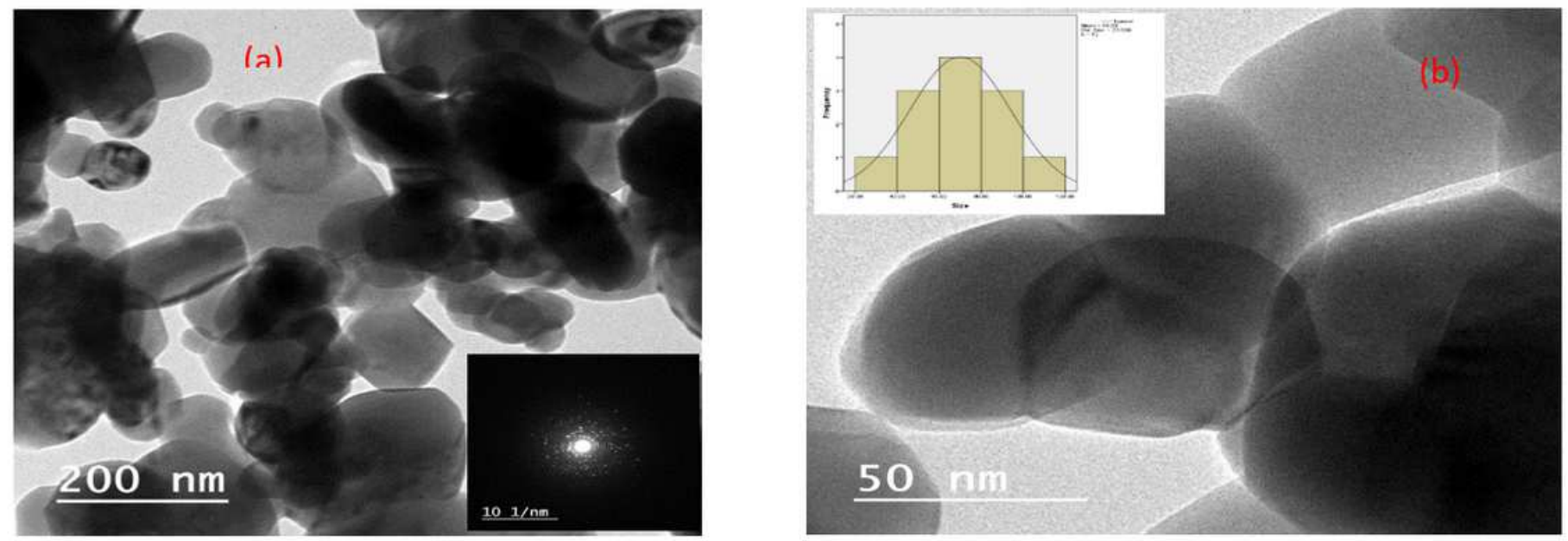

\section{Figure 3}

$a-b$ HRTEM with the selected area electron diffraction patterns (SAED) and histogram represents the size distribution for the Li1.1Co0.3Fe2.104.
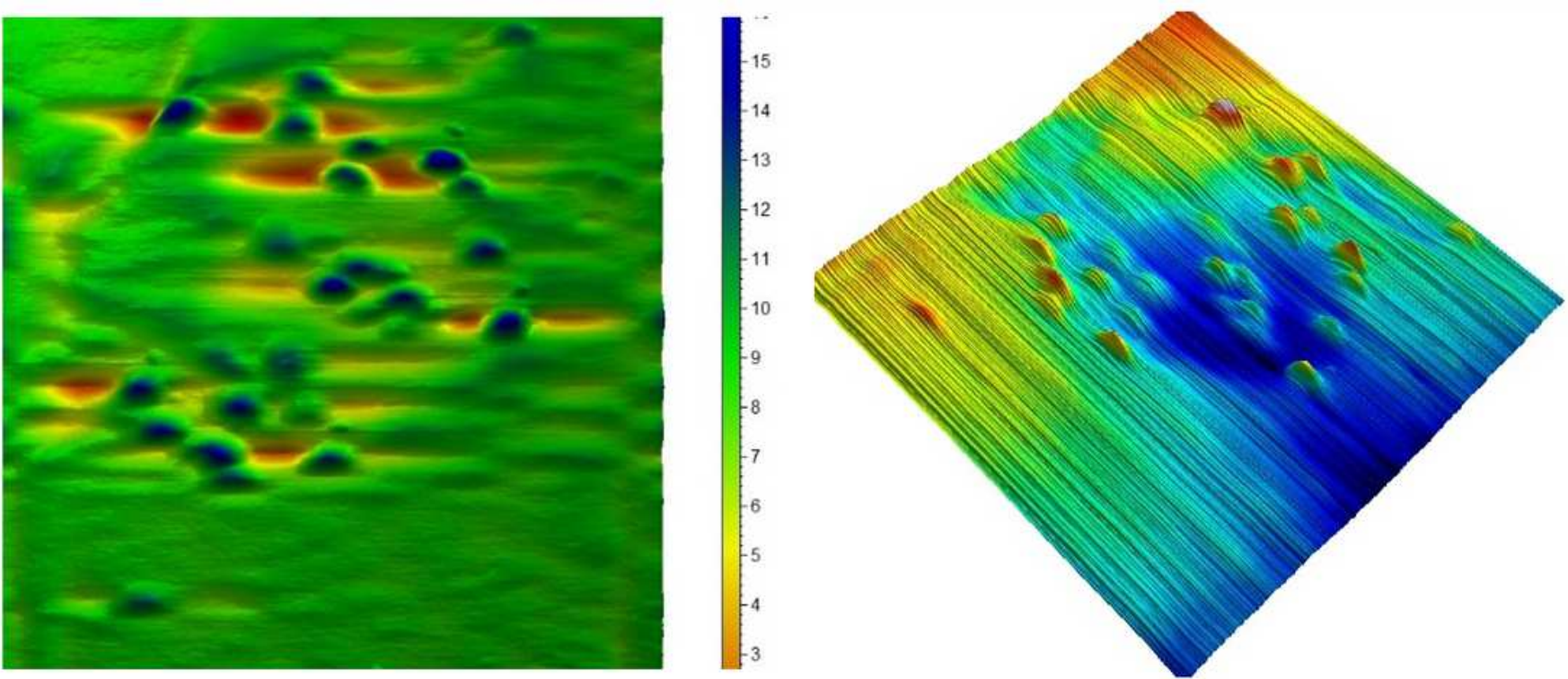

\begin{tabular}{|l}
-25 \\
24 \\
23 \\
22 \\
21 \\
-20 \\
19 \\
18 \\
$=17$ \\
-16 \\
-15 \\
14 \\
-13 \\
-12 \\
-11 \\
-10 \\
9 \\
8 \\
-7
\end{tabular}

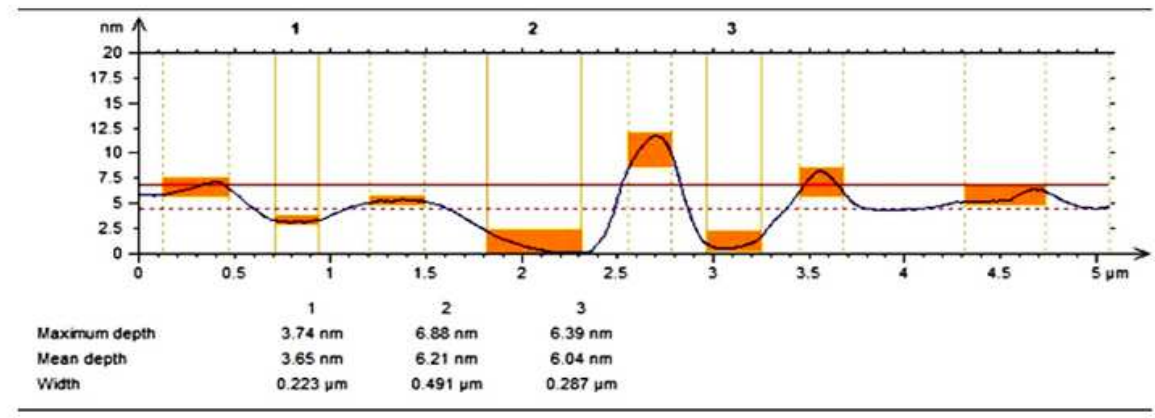

\section{Figure 4}

a-c AFM image of the Li1.1Co0.3Fe2.104 nano ferrite sample. 

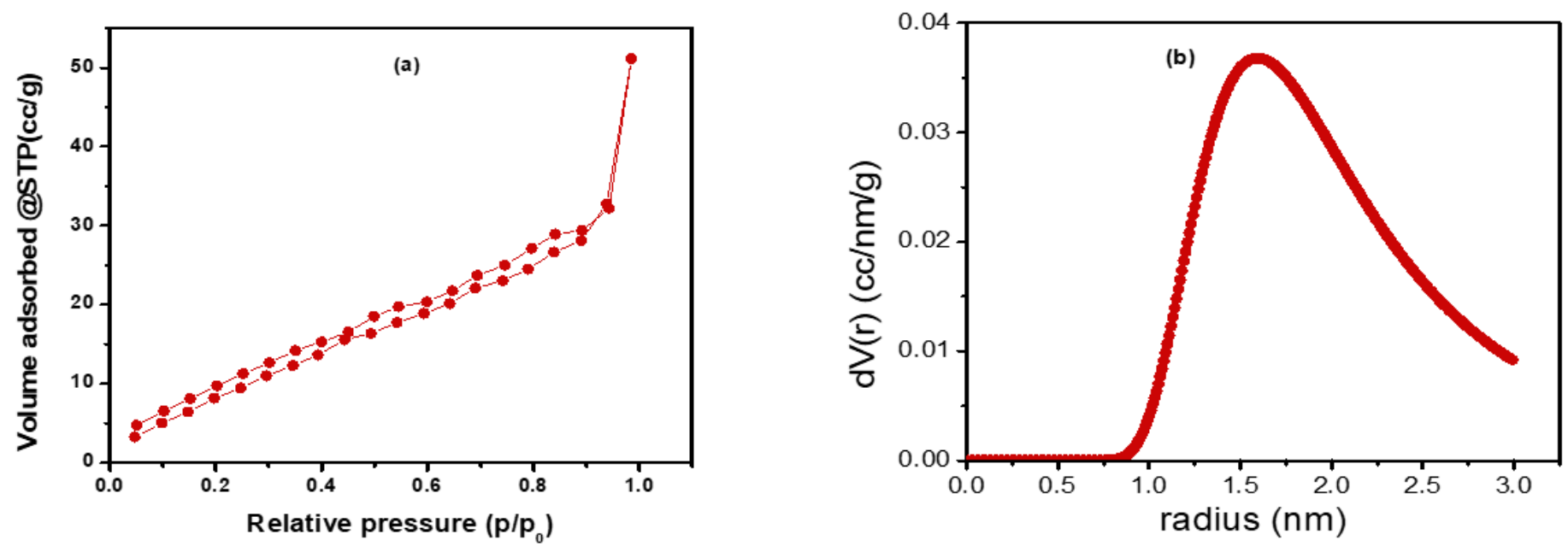

Figure 5

a-b Type of sorption isotherms and pores distribution of Li1.1Co0.3Fe2.104.
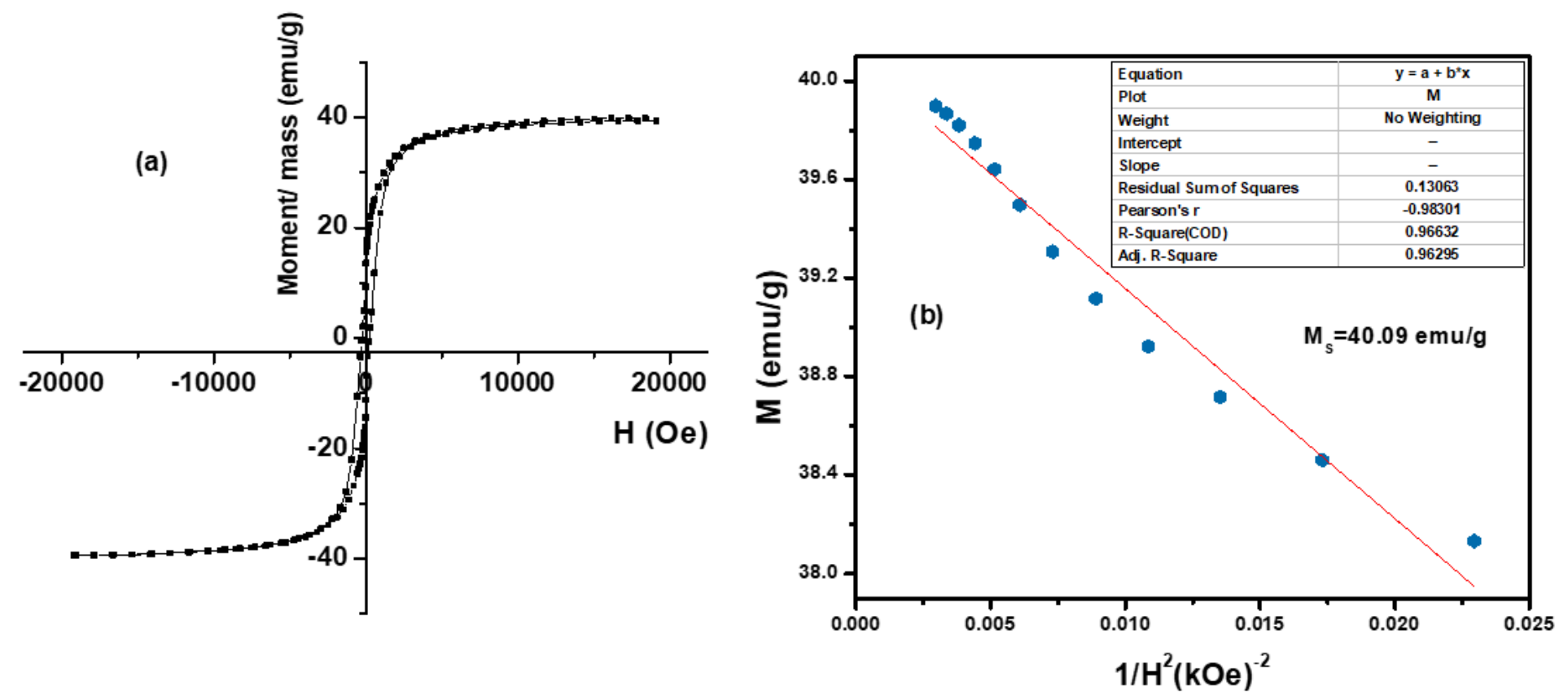

Figure 6

a-b VSM and fitting plot between M versus 1/H2 for Li1.1Co0.3Fe2.104 sample . 


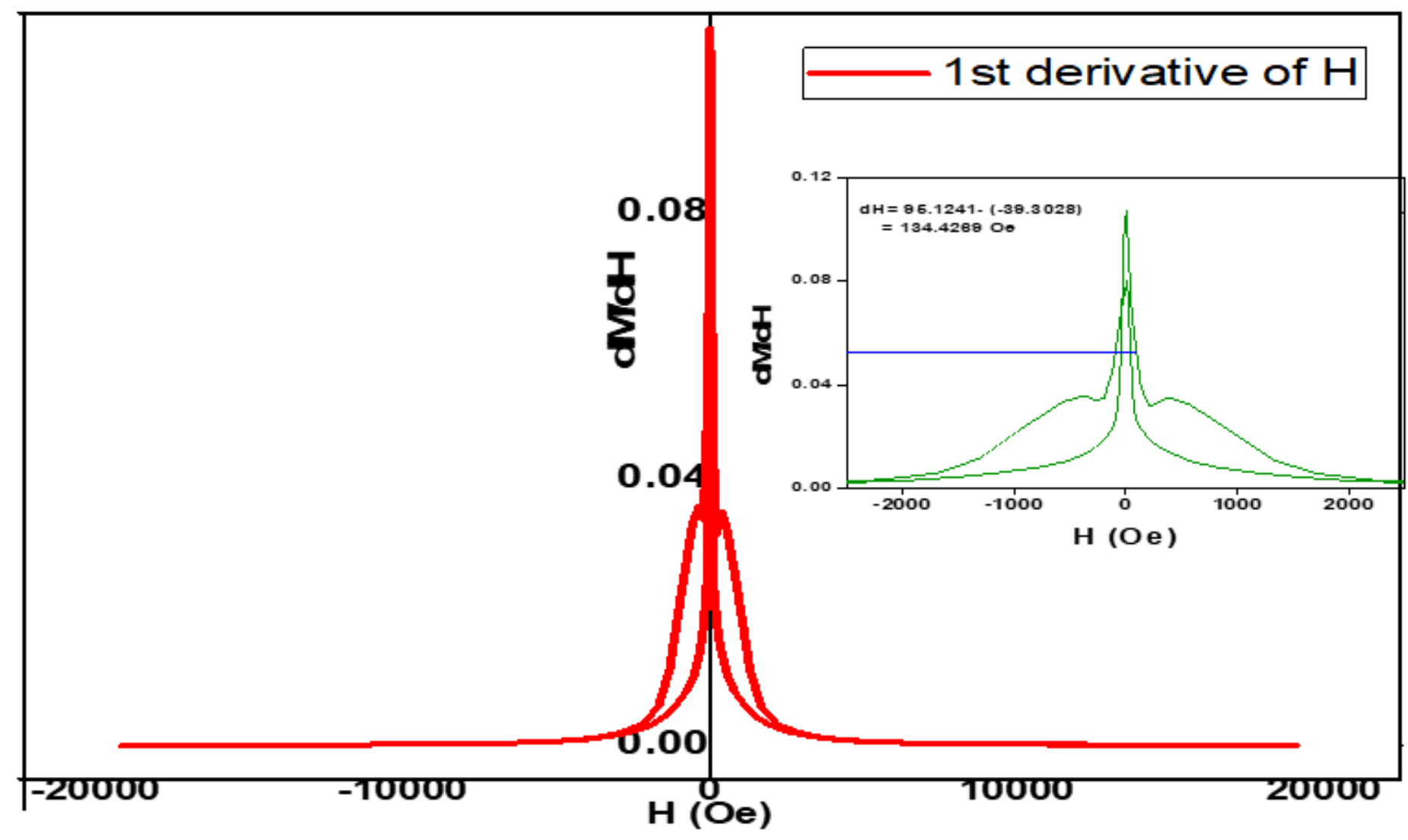

Figure 7

SFD value for the Li1.1Co0.3Fe2.104 as a function of coercivity.

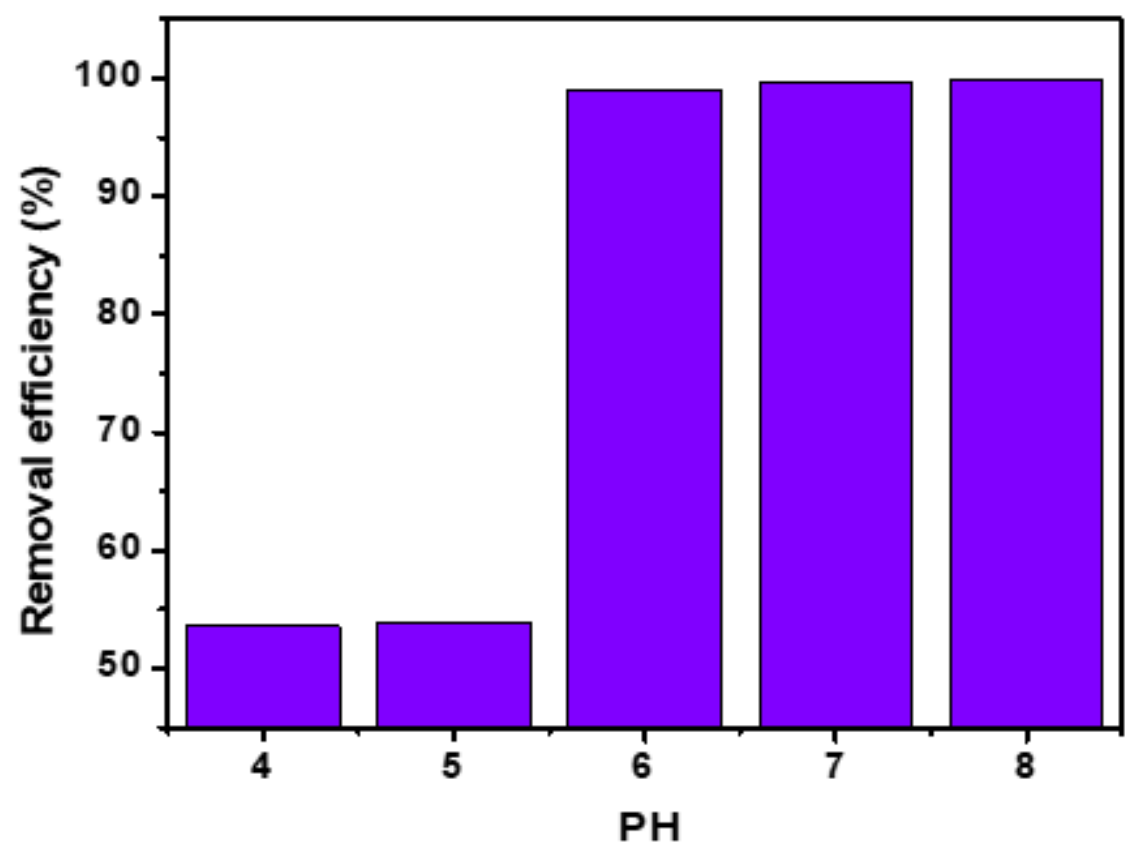

Figure 8 
Effect of $\mathrm{pH}$ on the adsorption efficiency of $\mathrm{Pb} 2+$ ions.
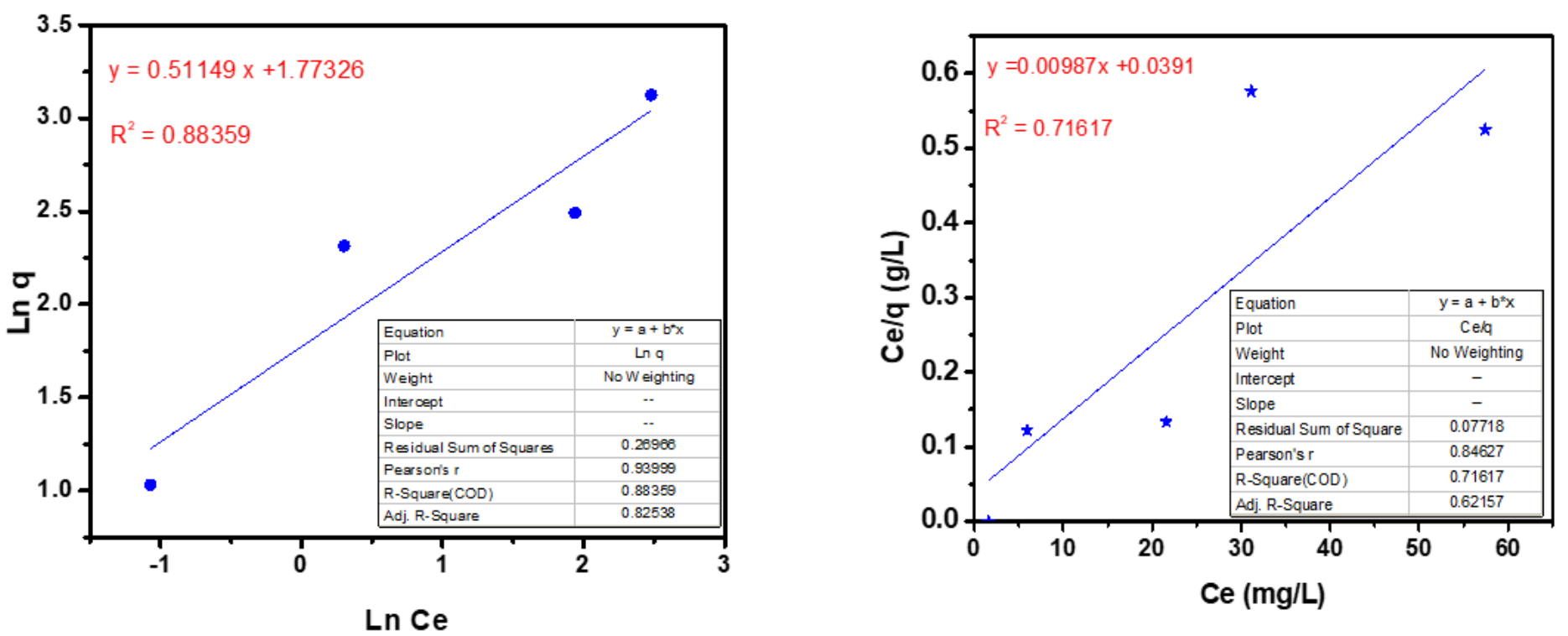

Figure 9

a-b Linear fits of experimental data of the adsorption of Pb2+ onto Li1.1Co0.3Fe2.104 (a) Langmuir and (b) Freundlich sorption isotherms. The inset various constants of the two models. 